\section{INVESTIGATION OF THE UPPER} ATMOSPHERE. with the investigation of the upper atmosphere forms part of a wide and well-organised scheme. On certain days appointed by an international committee, balloons and kites are sent up from some thirty stations scattered all over the world. The kites are used for the study of the lower layers, and free balloons for greater altitudes. In a discussion bearing on the isothermal layer we have therefore only to deal with the latter.

Abroad, instruments of many types have been designed and improved by Hergesell, Assmann, Teisserenc de Bort, and de Quervain. The fact that nearly

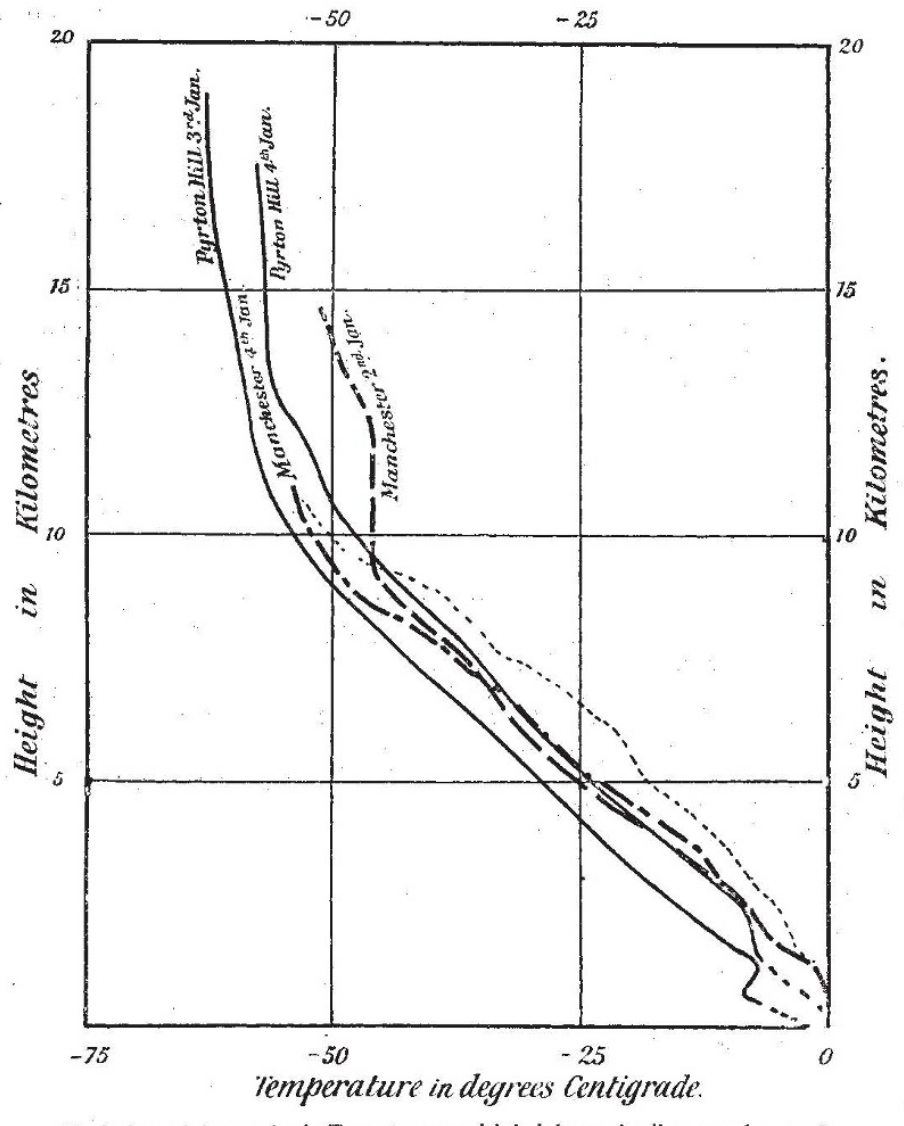

Variation of Atmospheric Temperature with height on April 2, 3 and 4, 7903.
THE work carried out in England in connection twenty different modifications exist is sufficient excuse

styles on a sheet of copper. This constitutes an important improvement, for the ordinary smoked record is not infrequently obliterated by the time the instrument is returned.

The record consists of fine lines, which remain parallel as long as the temperature remains constant. The bimetallic thermograph is carried on a support which is moved by the barograph. In ordinary circumstances a curve is obtained for any point of which the abscissa measures the deflection of the barograph, and the ordinate minus a constant the deflection of the thermograph.

The calibration of the thermograph is a simple matter, the deflection being practically a linear function of the temperature. The calibration of the barograph, on the other hand, offers considerable difficulties.

In order to increase the sensitiveness of the instrument without adding to its weight, it is necessary to leave a certain amount of air in the aneroid box. This, as also the change of elasticity of the metal, causes the calibration of the instrument to vary con. siderably with temperature, and adds materially to the labour involved in reducing the results.

After trying and abandoning various methods of approximation, Mr. W. A. Harwood, who is in charge of this branch of the work at Manchester, now draws out for each instrument a number of independent calibration curves, each one referring to one definite temperature. These form a series of nearly parallel curves, which cover the range of temperature and pressure over which the instrument is used. The calibration made before the ascent is verified after the return of the meteorograph.

The accuracy obtainable of course decreases with the density of the air ; over the first few kilometres a difference of level of less than a hundred metres is easily measured, but when the height attained is such that the prevailing pressure is only one-tenth of an atmosphere, the possible error becomes considerable.

The diagram here given, which refers to the last date on which balloons were sent up on three consecutive days, is a typical example of the results obtained. The Manchester record for January 2 lies between the Pyrton Hill curves for January 3 and 4 up to about $9 \mathrm{~km}$., above which height the temperature remains constant for some distance. Two traces were inscribed by the instrument sent up from Manchester on January 4. Probably in this case, as occasionally occurs, the balloon did not burst and fall at once on

for not undertaking here an analysis of their respective merits. These instruments cost from rol. to $12 l$., and their weight, which exceeds a pound, involves the use of relatively large and expensive balloons.

In Continental countries but few instruments are permanently lost, and as very substantial Government grants are in most cases available, the question of working expenses is not of vital importance. In England we are financially and geographically less favourably situated, and there is little doubt that but for the energy and inventive genius of one man, little work would have been attempted.

The Dines balloon meteorograph costs one-tenth and weighs one-eighth of the corresponding Continental instruments. The record, though microscopic, is nearly indestructible, for it is engraved by two sharp attaining the maximum height, but drifted down slowly as the gas diffused out. In such cases the time to which the second trace applied cannot be determined, and the rise of temperature might well be due to the next day's solar radiation. Trustworthy or otherwise, this trace has its place on the present diagram, the primary object of which is to give a complete collection of the results obtained from one set of ascents. The Pyrton Hill balloons were sent up at 3 p.m., and the Manchester ones at 6 p.m.

It is noticeable that during the three days the average temperature gradients between 2 and 8 kilometres (i.e. above the disturbing influence of the remained practically constant, whereas a considerable ground, but below the level of the isothermal layer) NO. 2012 , VOL. 787 
difference existed between the temperature of the isothermal layer as measured on January 2 and 3 .

Generally speaking, many improvements of the methods and instruments are doubtless still required, but it must be remembered that the work in England was commenced less than a year ago, and perfection can hardly be expected within so short a time.

J. E. Petavel.

\section{HOME AND FOREIGN BIRD-LIFE.}

THE authors of these three excellent little works are evidently enthusiastic bird-lovers and accomplished and patient observers. In the case of the first two, at any rate, their highest enjoyment appears, indeed, to consist in sitting for hours watching the movements and ways of their feathered favourites. Moreover, either they or their friends are well accomplished in the use of the camera, and they have thereby been enabled to make permanent records of many of the fascinating sights that have come under their observation for the benefit of those who have neither their patience nor their opportunities.

Mr. Gordon's favourite species appear to be the golden eagle and the ptarmigan, the photographs of both of which are claimed to be nearly, if not indeed completely, unique. To obtain the picture of the golden eagle's eyrie the author underwent considerable difficulty not unmingled with danger, while peril of another type was experienced when a fog suddenly descended as he was wandering among snow-clad precipices in search of ptarmigan. The photographs have therefore more than their apparent face-value, which is of itself considerable. Where all are interesting it is difficult to make a selection, although personally we have been much interested in the series of photographs of a young golden eagle at various stages of growth, one of which is here reproduced.

Mr. Charles Barrett, in "From

Range to Sea," covers comparatively new ground, and has attempted to accomplish for some of the birds of Australia what has already been done for those of our own islands. It must be confessed, however, that the illustrations in his booklet (whether from the fault of the photographs themselves, of the reproductions, or of the printer we cannot say) are by no means up to the level of those in some books of English birdlife. In the tiny and exquisitely built nests of such species as the rufous and the white-shafted fantail, with the parent-bird in attendance, the author has subjects quite different from any met with in this country, and in portraying these novelties he appears to have availed himself to the full of his opportunities. The nest of the lyre-bird forms, perhaps, a still more striking; subject, which was the scene of an altogether

1 "Birds of the Loch and Mountain." By Seton P. Gordon. Pp. xvi $+\mathrm{r} 8 \mathrm{r}$; illustrated. (London: Cassell and Co., Ltd., r907.) Price $7 s .6 \%$. net.

"From Range to Sea ; a Bird-lover's Ways." By C. Barrett. Pp. 62 ; illustrated. (Melbourne: T. C. Lothian, 1907.) Price $1 s$.

"Sketches of South African Bird-life." By A. Haagner and R. H. Ivy. Pp. xxiv $+\mathrm{r}_{\mathrm{r}}$; illustrated. (London: R. H. Porter, rgo?.) Price zos. net. NO. 2OI2, VOL. 78$]$ unexpected incident. "On inserting my hand in the nest," writes the author, "a piercing cry, like the whistle of a steam-engine, rang down the gully. It was difficult to realise that the half-fledged lyre-bird which I could feel inside the nest was the cause of this unearthly clamour."

The present booklet is an excellent beginning in Australian bird-photography, and we shall look in the future for more work in the same style from the author and his artist, Mr. Mattingley.

The book standing third on our list is of a somewhat different type from either of the two already noticed, presenting in some degree an approximation to a popular history of South African birds generally. It may serve, in fact, as a kind of popular representative of the volumes on birds in the "Fauna of South Africa," and should be of the greatest value to a large number of persons who for one reason or another are unable to refer to the latter. Indeed, by means of the numerous excellent photographs with which it is illustrated, this volume will enable the sportsman and amateur naturalist in South Africa to

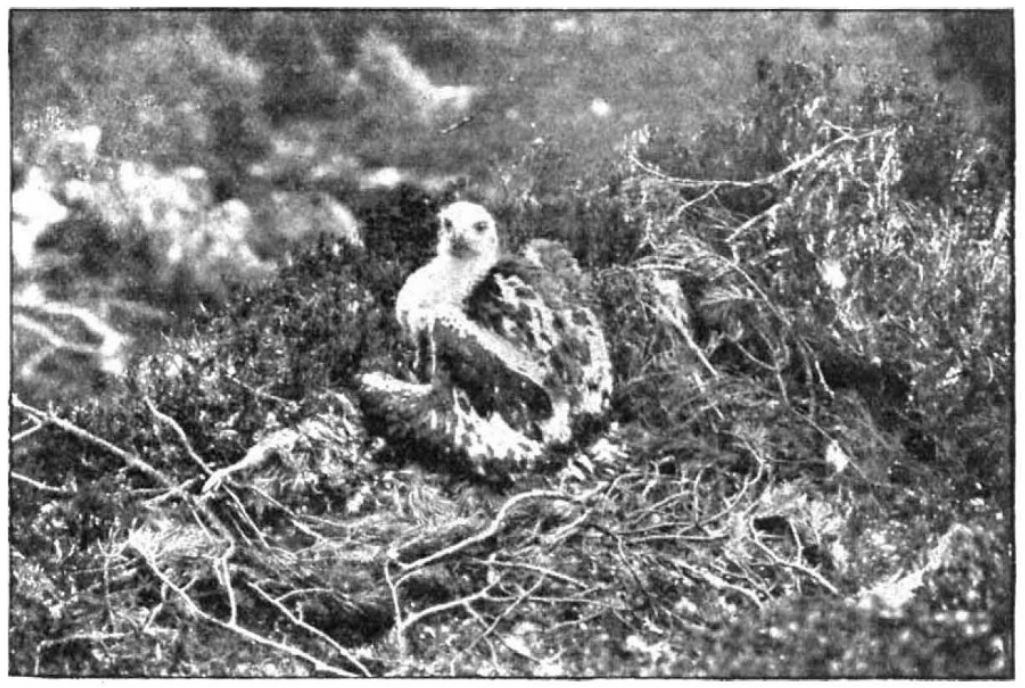

FIG. I.-Golden Eagle six weeks old. The bird fell from the original eyrie and is here shown in one made by parent birds at the foot of the cliff. From "Birds of the Loch and Mountain."

determine without any great difficulty a very considerable proportion of the birds with which he may be brought in contact. The illustrations (of which a sample is reproduced) are for the most part excellent, while the text contains a sufficient amount of anecdote and local colouring to redeem it from the charge of dulness.

Personally we have found special interest in the author's account of the eggs and parasitic habits of the honey-guides and cuckoos. Honey-guides, it appears, actually storm the breeding-holes of the species upon which they are parasitic, as was witnessed by the author in the case of a pair of barbets, which offered a fierce resistance to the intruder. As regards cuckoos, it is absolutely certain that in South Africa these birds must generally lay their eggs on the ground and transport them in their beaks to the foreign nests, which they are too large to enter. All the African cuckoos normally lay coloured eggs, but when they lay in nests of species with white eggs, their own eggs are also often white. In the case of the golden cuckoo the author states that " a pure white egg was taken from the oviduct of a female 